Skin

Appendage

Disorders
Skin Appendage Disord 2017;3:64-66

DOI: $10.1159 / 000452976$
Received: October 12, 2016

Accepted: October 31, 2016

Published online: February 11, 2017

\title{
Temporal Triangular Alopecia in Children: The Same Clinical Feature for Two Distinct Entities
}

\author{
Awatef Kelati Hannane Baybay Fatima Zahra Mernissi \\ Department of Dermatology, University Hospital Hassan II, Fez, Morocco
}

\section{Question}

Two Moroccan girls, a 10-year-old (first case: Fig. 1a) and an 11-year-old (second case: Fig. 1b), were referred to the Department of Dermatology at the University Hospital Hassan II, Fez, for a 4-year and 10-year history of asymptomatic hair loss. Physical examination revealed the presence of frontal-temporal triangular alopecia, without any scales or erythema. The pull test was negative, and the rest of the clinical examination was normal.

What is your diagnosis?
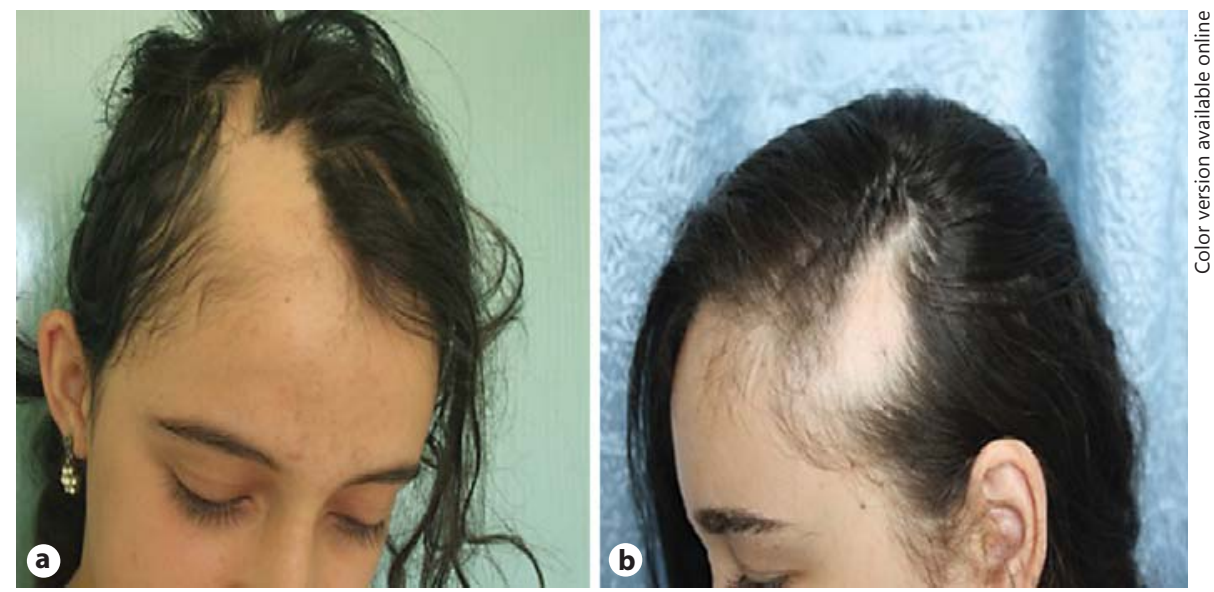

Fig. 1. Temporal triangular alopecia in two cases. a Case 1. b Case 2.

Awatef Kelati, MD

Department of Dermatology, University Hospital Hassan II 202 Hay Mohamadi

Fez (Morocco)

E-Mail awatkelati@gmail.com 


\section{Answer}

In the first case: alopecia areata based on dermoscopic findings: non-scarring alopecia with features of yellow and black dots, exclamation mark hair, cadaveric hair, broken hair, coudability hair, vellus hair (Table 1; Fig. 2).

In the second case: congenital temporal triangular alopecia based on the history (since the first year of birth), and dermoscopy: non-scarring alopecia with features of a tuft of hairs and short vellus hairs of different length (Fig. 3).
Congenital triangular alopecia, also called temporal triangular alopecia, is an asymptomatic permanent circumscribed noncicatricial alopecia. It manifests as an alopecic patch without any underlying cutaneous alterations usually confined to one frontotemporal region of the scalp. Fine vellus hairs may be present. It is usually noted in children between 3 and 6 years of age. Its genetic basis is unknown, but a paradominant trait is suspected [1].

The diagnosis of congenital triangular alopecia is predominantly clinical, with features of non-scarring alopecia of variable size, usually unilateral and located predom-

Fig. 2. Dermoscopic examination of the temporal triangular alopecia in the first case revealing features of alopecia areata.
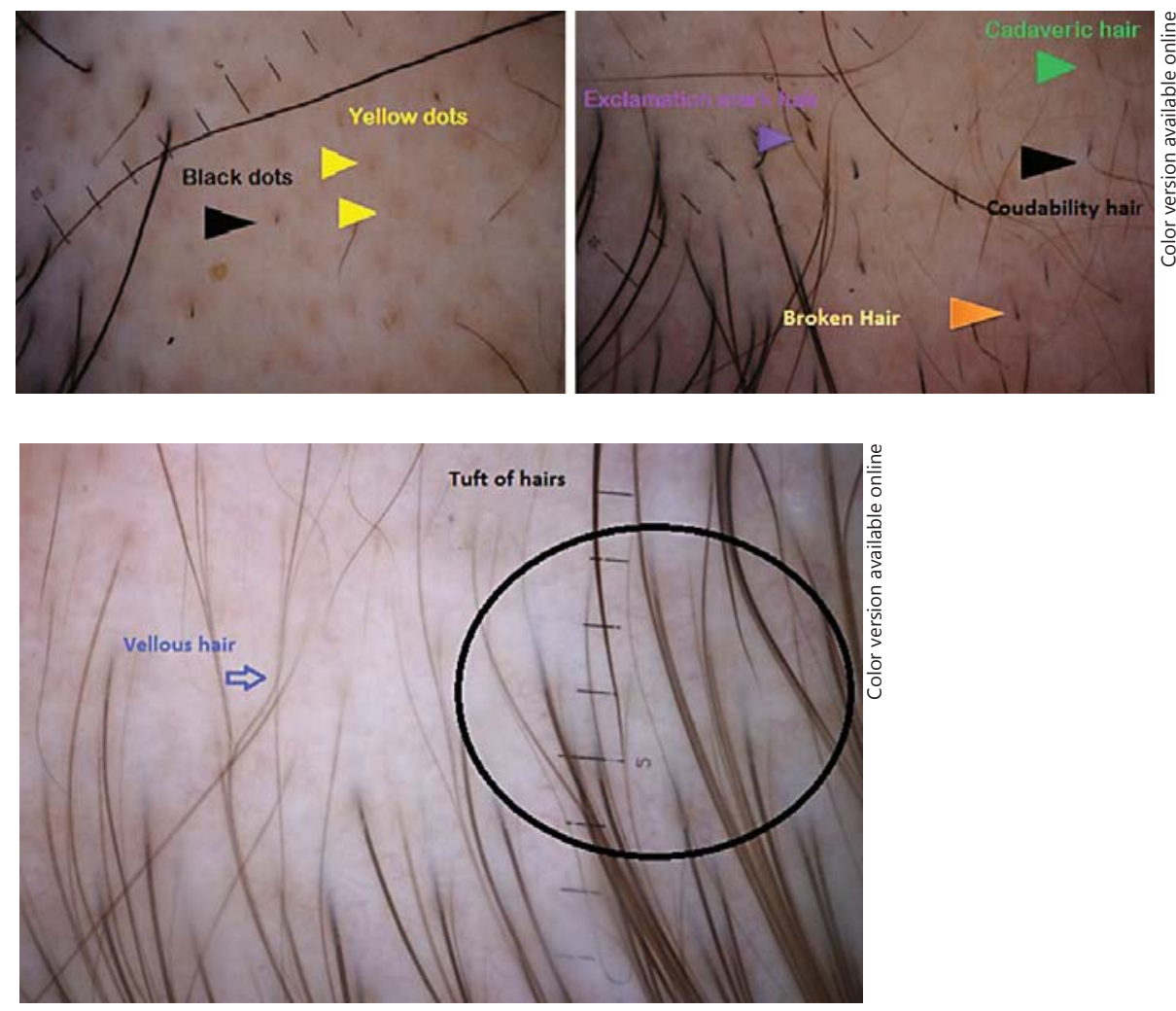

Fig. 3. Dermoscopic examination of the temporal triangular alopecia in the second case revealing features of congnital temporal triangular alopecia.

Table 1. Significance of the dermoscopic features seen in the two cases

\begin{tabular}{ll}
\hline Dermoscopic signs & Definition \\
\hline Yellow dots & $\begin{array}{l}\text { Round yellow dots that may be devoid of hairs or contain miniaturized, cadaveric, or dystrophic } \\
\text { hairs }\end{array}$ \\
Black dots & $\begin{array}{l}\text { Pigmented hairs broken or destroyed at the scalp level } \\
\text { Broken hairs }\end{array}$ \\
Vellus hairs & Thin hair that results from hair regrowth either spontaneously or as a result of treatment \\
Exclamation mark hair & The hair shaft is fractured and short with an important proximal diameter \\
Cadaveric hair & Short twisted thin dead hairs \\
Coudability hair & Normal-looking hairs tapered at the proximal end \\
Tuft of hair & A cluster of vellus hairs held together \\
\hline
\end{tabular}


inantly $(86.6 \%)$ on the frontotemporal suture [2]. The major differential diagnoses are the non-cicatricial circumscribed alopecias including alopecia areata, trichotillomania, traction alopecia, and aplasia cutis congenita [1].

Trichoscopy is now proven [3] to be of great help to differentiate dermatological conditions that are clinically similar, like in these two similar cases of temporal triangular alopecia. In the first case, dermoscopy had shown dermoscopic features of alopecia areata, while in the second case, the diagnosis of congenital triangular alopecia was confirmed.

\section{Statement of Ethics}

The two patients were informed and gave their consent to describe their cases.

\section{Disclosure Statement}

The authors declare no conflicts of interest. There were no funding sources for this work.

Keywords

Temporal triangular alopecia · Clinical challenge ·

Dermoscopy

\section{References}

1 Fernández-Crehuet $\mathrm{P}$, Vaño-Galván S, Martorell-Calatayud A, Arias-Santiago S, Grimalt $\mathrm{R}$, Camacho-Martínez FM: Clinical and trichoscopic characteristics of temporal triangular alopecia: a multicenter study. J Am Acad Dermatol 2016;75:634-637.
2 Yamazaki M, Irisawa R, Tsuboi R: Temporal triangular alopecia and a review of 52 past cases. J Dermatol 2010;37:360-362.

3 Karadağ Köse Ö, Güleç AT: Temporal triangular alopecia: significance of trichoscopy in differential diagnosis. J Eur Acad Dermatol Venereol 2015;29:1621-1625. 